CZU 343.4

https://doi.org/10.52507/2345-1106.2021-2.13

УГОЛОВНАЯ ОТВЕТСТВЕННОСТЬ ЗА НАРУШЕНИЕ РАВНОПРАВИЯ ГРАЖДАН В УКРАИНЕ И МОЛДОВЕ: КОМПАРАТИВИСТСКИЙ ПОДХОД

ПАНЬКЕВИЧ Василий, кандидат юридических наук, доцент, доцент кафедры права

Винницкий торгово-экономический институт КНТЭУ,

(Украина)

vasiliy2112@ukr.net https://orcid.org/0000-0003-0298-0033 


\title{
АННОТАЦИЯ
}

В статье проводиться сравнительный анализ уголовного законодательства Украины и Молдовы в сфере обеспечения равноправия граждан. Определены составы уголовных правонарушений, которые предусматривают ответственность за посягательство на общественные отношения в сфере общеправового принципа равноправия граждан. Выявлены прогрессивные аспекты и отдельные недостатки законодательных конструкций указанных составов уголовных правонарушений, которые необходимо учесть в процессе усовершенствования уголовного законодательства обоих стран.

Ключевые слова: преступление, уголовная ответственность, равноправие граждан, разжигание вражды, наказание.

\section{CRIMINAL RESPONSIBILITY FOR VIOLATION OF EQUALITY OF CITIZENS IN UKRAINE AND MOLDOVA: COMPARATIVIST APPROACH}

Vasyl PANKEVYCH,

$\mathrm{PhD}$ in Science of Law, Associate Professor, Associate Professor of the Department of Law Vinnytsia Institute of Trade and Economics of KNUTE,

(Ukraine)

vasiliy2112@ukr.net

https://orcid.org/0000-0003-0298-0033

\begin{abstract}
SUMMARY
The article provides a comparative analysis of the criminal legislation of Ukraine and Moldova in the field of ensuring equality of citizens. The composition of criminal offenses has been determined, which provide for responsibility for encroachment on public relations in the field of the general legal principle of equality of citizens. The progressive aspects and individual shortcomings of the legislative structures of the indicated compositions of criminal offenses are revealed, which must be taken into account in the process of improving the criminal legislation of both countries.
\end{abstract}

Key words: crime, criminal responsibility, equality of citizens, incitement to hatred, punishment.

Постановка проблемы в общем виде. Уголовные преступления, совершенные по мотивам предубеждения или ненависти относящейся к определенной социальной общности из-за наличия или отсутствия у нее определенных социальных признаков, имеют серьезные последствия как для отдельных представителей таких сообществ, так всего сообщества, и могут перерастать в более масштабные конфликты. В связи с этим, уголовные правонарушения на почве ненависти, несмотря на их относительно небольшую распространенность, следует признавать составляющими особую угрозу для стабильности и социального равновесия в любом государстве. В Украине, как и в остальном мире, по наблюдению Бюро по демократическим институтам и правам человека ОБСЕ (БДИПЧ) наблюдается чрезвычайно высокий уровень (заявление подается только по каждому пятому случаю) латентности уголовных правонарушений, совершаемых почве ненависти $[1$, с.5]. Эффективное противодействие нарушению равноправия граждан, в частности, правильная правовая квалификация таких действий, а также оперативное привлечение виновных к ответственности будут способствовать укреплению чувства правовой защищенности социальных групп со стороны правоохранительных органов и обеспечивать социально-политическую стабильность в государстве.

Анализ последних исследований и публикаций. Значительный вклад в теоретическую разработку проблемы уголовной ответственности за нарушение равноправия граждан осуществили такие ученые в области уголовного права как П. Андрушко, Ю. Баулин, В. Борисов, И. Зинченко, А. Колб, Д. Колодин, С. Лиховая, М. Палий, Н. Панов, Г. Рыбальченко, А. Савченко, В. Сташис, В. Таций, Н. Хавронюк, С. Шмидт, Дж. Якобс и другие. Однако, растущая эмпирическая база, состоящая из зарегистрированных уголовных производств и рассмотренных судами дел в этой сфере, обусловливают дальнейшие научные исследования этой проблемы.

Целью статьи является проведение научного сравнения уголовной ответственности за нарушение равноправия граждан в Украине и Молдове.

Изложение основного материала. Граждане имеют равные конституционные права и свободы, и равны перед законом; не может быть привилегий или ограничений по признакам расы, цвета кожи, политических, религиозных и других убеждений, пола, этнического и социального происхождения, имущественного состояния, местожительства, по языковым или другим признакам; каждый имеет право на свободу мировоззрения и вероисповедания (статьи 24 и 35 Конституции Украины) [2]. Аналогичные положения содержатся в статье 16 Конституции Республики Молдова [3].

С целью надежной защиты этого конституционного принципа украинский законодатель установил уголовную ответственность за нарушение равноправия граждан в зависимости от их расовой, национальной принадлежности, религиозных убеждений, инвалидности и по другим признакам (далее - нарушение равноправия 
граждан) в ст. 161 УК Украины [4]. В Уголовном кодексе Республики Молдова уголовная ответственность за нарушение равноправия граждан предусмотрена в ст.176 раздела V «Преступления против политических, трудовых и других конституционных прав граждан» [5].

$$
\text { Проводя сравнительный }
$$

анализ

непосредственных объектов вышеупомянутых составов уголовных преступлений следует отметить, что в ст.176 УК Республики Молдова под уголовно-правовую защиту поставлено исключительно общественные отношения в сфере обеспечения конституционного принципа равноправия и противодействия любым дискриминационным проявлениям. Таким образом, название уголовно-правовой статьи и содержание ее диспозиции полностью совпадают, что соответствует требованиям к логикосемантическому конструированию правовых норм.

Вместе с тем, как нами отмечалось ранее, поставленные в ст.161 УК Украины под охрану общественные отношения, не является однородным. Одни из них, направленные на обеспечение правового статуса соответствующих субъектов (в частности, граждан Украины) в части соблюдения принципа их равноправия при реализации ими конституционных прав и свобод; другие - на обеспечение внутренней безопасности Украины, то есть на соблюдение межрасового, межнационального, межрелигиозного мира и согласия в государстве, и входят в состав общественных отношений, составляющих основы национальной безопасности Украины. Поэтому, вид и объем общественных отношений, на которые распространяется уголовно-правовая охрана в ст.161 УК Украины, не совпадают с названием этой статьи (значительно шире по своему содержанию).

Уголовное преступление, ответственность за которое предусмотрена ч.1 ст.161 УК Украины, сконструировано с усеченным составом, то есть уголовное преступление считается завершенным в момент совершения соответствующего действия, а его последствия находятся вне состава уголовного преступления и, в данном случае, на квалификацию не влияют. Содержание п. (1) ст.176 УК Республики Молдова позволяет сделать вывод, что в данной норме содержится несколько альтернативных составов уголовных правонарушений, которые по своему характеру являются как формальными, так и материальными. В частности, нарушение равноправия граждан, совершенное должностным лицом или с размещением дискриминационных сообщений и символов в общественных местах, или по двум или более признакам, или двумя или более лицами, являются уголовными правонарушениями с формальным составом. Вместе с тем, нарушение равноправия граждан, причинившее ущерб в крупных размерах, является уголовным правонарушением с материальным составом.

Нарушение равноправия граждан в украинском законодательстве отнесено к категории нетяжелых преступлений и за его совершение предусмотрено основное наказание в виде штрафа, ограничения свободы или лишения свободы, а также дополнительное необязательное наказание в виде лишения права занимать определенные должности или заниматься определенной деятельностью. Рассматриваемое нами уголовное преступление законодатель Республики Молдова отнес к категории незначительных преступлений и предусмотрел наказание практически схожие виды наказаний: штраф, бесплатная работа на пользу общества или лишения свободы (основные), а также аналогичное дополнительное необязательное наказания.

Квалифицированный состав нарушение равноправия граждан, содержится в ч.2 ст.161 УК Украины, предусматривает следующие квалифицирующие признаки: насилие, обман и совершение должностным лицом, относится к нетяжелым преступлениям, а также предусматривает аналогичные части 1 настоящей статьи виды наказаний. Пункт (2) ст.176 УК Республики Молдова, учитывая виды и размер наказаний сконструирован, как привилегированный состав, и устанавливает уголовную ответственность за пособничество или подстрекательство в виде поощрения или поддержки нарушение равноправия граждан через средства массовой информации. Такое деяние наказывается штрафом или бесплатной работой на пользу общества (для физических лиц), а также штрафом и лишением права заниматься определенной деятельностью (для юридических лиц).

Часть 3 ст.161 УК Украины содержит особо квалифицированный состав нарушение равноправия граждан, где квалифицирующими признаками являются совершение этого уголовного преступления организованной группой лиц или причинение им тяжких последствий. Учитывая вид и размер наказания, такое уголовное преступление следует отнести к тяжким преступлениям. Пункт (3) ст.176 УК Республики Молдова содержит квалифицированный состав уголовного преступления, предусматривающих ответственность за нарушение равноправия граждан, которое повлекло неосторожную смерть человека или его самоубийство. Учитывая вид и размер наказания, указанного состава уголовного преступления, следует отнести его к категории тяжких преступлений.

Возвращаясь к вопросу неоднородности общественных отношений, которые поставлены под уголовно-правовую охрану в ст.161 УК Украины, следует отметить, что нами, в рамках выводов диссертационного исследования, было предложено исключить из ч.1 ст. 161 УК Украины три формы совершения этого уголовного преступления (прежде всего из-за разного родовой и непосредственного объектов посягательства, особенностей конструкции их объективной стороны, законодательное указание на смежные с ним действия в ч. 2 ст. 110 УК Украины и т.д.), и закрепить их в новой ст. 110-1 "Агитация и 
пропаганда расовой, национальной или религиозной нетерпимости" УК Украины в следующей редакции: "Агитация или пропаганда, направленные на возникновение расовой, национальной или религиозной нетерпимости» (при этом под "агитацией" следует понимать распространение идей и взглядов среди широкого круга людей, как правило, публично, а под "пропагандой" распространение идей и взглядов среди узкого, корпоративного круга лиц). Квалифицирующими признаками данного состава уголовного преступления в ст. 110-1 УК Украины предлагалось признать: а) совершение этого уголовного преступления лицом, которое является представителем власти; б) повторно; в) по предварительному сговору группой лиц; г) с использованием средств массовой информации, компьютерных сетей или сетей электросвязи; г) в сочетании с призывами к насилию; особенно квалифицирующими признаками: а) действия, предусмотренные частями первой или второй настоящей статьи, совершенные организованной группой; б) если они повлекли тяжкие последствия. Санкция по ч.1 ст. 110-1 УК Украины должна соответствовать санкции за нетяжкие преступления, по ч. 2 ст.110-1 - санкции за тяжкое преступление по ч. 3 ст. 110-1 - санкции за особо тяжкое преступление [6, с.15]. Вышеупомянутые предложения автором в 2010 году были направлены в Верховную Раду Украины, однако с тех пор ст.161 УК Украины претерпела совсем незначительных, не концептуальных редакционных изменений. Вместе с тем, отсутствие в национальном правовом поле Украины нормы, предусматривающей уголовную ответственность за агитацию или пропаганду, направленные на возникновение нетерпимости на языковой, национальной и религиозной почве, до сих пор не позволяет правоохранительным органам эффективно противодействовать таким деянием, наносящим ущерб национальной безопасности и территориальной целостности государства.

Ярким подтверждением необходимости внесения законодательных изменений в действующий УК Украины является наличие в Главе XVII «Преступления против публичной власти и безопасности государства» УК Республики Молдова статьи 346 «Умышленные действия, направленные на разжигание национальной, этнической, расовой или религиозной вражды, дифференциации или раздора». Диспозиция этой нормы предусматривает уголовную ответственность за умышленные действия, публичные призывы, в том числе через печатные и электронные средства массовой информации, направленные на разжигание национальной, этнической, расовой или религиозной вражды, дифференциации или раздора, на унижение национальной чести и достоинства, а равно прямое или косвенное ограничение прав или установление прямых или косвенных преимуществ граждан в зависимости от национальной, этнической, расовой или религиозной принадлежности.
Подчеркивая прогрессивный характер существования этой нормы, следует заметить на наличии, по нашему мнению, отдельных дискуссионных моментов в ее конструкции. Так, одним из обязательных требований, которое предъявляется к уголовно-правовой нормы, является то, чтобы эта норма и модель поведения, в ней содержатся, должны быть сформулированы с максимальной точностью [7, с.24]. Понятийный аппарат Особенной части УК должен иметь следующие качества: официальный характер, четкость, ясность, единство терминологии, краткость [8, с.164]. Как удачно отмечают криминалисты Н. Карпушин и В. Курляндский, что признаки преступления в его составе должны быть в определенной степени формализованы, переведены на юридический язык, выраженные в уголовноправовых понятиях, однозначные и включены в систему юридических понятий и категорий [9, с.45] Таким образом, термин «разжигание» имеет как прямое значение - определенный физикохимический процесс, так и переносное, в котором и используется в диспозиции нормы. Оперирования этим термином на практике может вызвать определенные трудности в процессе его толкования и при квалификации совершенных общественно опасных деяний, что, в свою очередь, это может привести к ошибкам в ходе правоприменительного процесса.

Обращает на себя внимание и то, что законодатель Республики Молдова предусмотрел уголовную ответственность за умышленные действия, направленные на разжигание национальной, этнической, расовой или религиозной вражды, дифференциации или раздора, то есть только в отношении принадлежности или непринадлежности лиц к группам по одной или несколькими из четырех социальных признаков: национальность, этнос, раса или религия. При этом, вне уголовно-правовой охраной остается право граждан принадлежать к определенной социальной группе по другим признакам, в частности, принадлежность к определенной языковой общности, профессии, сексуальных предпочтениях, наличие определенной болезни и тому подобное. То же самое касается такой формы совершения этого уголовного преступления как прямое или косвенное ограничение прав или установление прямых или косвенных преимуществ граждан.

Кроме этого, часть правовой нормы, которая размещена в ст.346 УК Республики Молдова, предусматривает, по нашему мнению, уголовноправовую охрану общественных отношений, связанных с обеспечением принципа равноправия граждан, в частности, в форме прямого или косвенного ограничения прав или установление прямых или косвенных преимуществ граждан в зависимости от национальной, этнической, расовой или религиозной принадлежности.

Таким образом, на наш взгляд, при квалификации возникает конкуренция общей и специальной уголовно-правовых норм. Например, в 
случае установления различий, исключение, ограничение или преимущества в правах и свободах человека или группы лиц, поддержка дискриминационного поведения в политической, экономической, социальной, культурной и других сферах жизни по признакам расы, национальности, этнического происхождения или религии, содеянное следует квалифицировать по ст.346 УК Республики Молдова. При этом, поощрения или поддержка таких действий через средства массовой информации находятся вне состава вышеупомянутого уголовного преступления и требует квалификации с использованием институтов предварительной преступной деятельности и соучастия. Также вне состава этого уголовного преступления находятся случаи, повлекшие неосторожное гибель человека или его самоубийство, что, для учета этих обстоятельств, требует квалификации действий виновного (них) по совокупности с другими уголовно-правовыми нормами. В противном случаи, учитывая размер максимальных наказаний, ст.346 УК Республики Молдова будет привилегированным составом относительно п. (3) ст.176 УК Республики Молдова.

Также обращает на себя внимание то, что, в случае установления различий, исключение, ограничение или преимущества в правах и свободах человека или группы лиц, поддержка дискриминационного поведения в политической, экономической, социальной, культурной и других сферах жизни по признакам языка, убеждений, пола, возраста, ограниченных возможностей, взглядов, политической принадлежности или на основании любой другой признаки, если оно было совершено без наличия хотя бы одного из таких признаков как совершенное должностным лицом, нанесло ущерб в значительном размере, путем размещения дискриминационных сообщений и символов в общественных местах, совершенное по двум или более признакам или двумя или более лицами, в действиях лица вообще отсутствует состав нарушения равноправия. Если деяние без наличия вышеуказанных признаков касалось установления различий, исключение, ограничение или преимущества в правах и свободах человека или группы лиц, поддержки дискриминационного поведения в политической, экономической, социальной, культурной и других сферах жизни по признакам расы, национальности, этнического происхождения или религии, то содеянное следует квалифицировать по ст.346 УК Республики Молдова.

Стоит отметить, что с целью реформирования законодательства Украины, в том числе уголовного, Указом Президента Украины № 584/2019 от 7 августа 2019 создана Комиссия по вопросам правовой реформы, частью которой является Рабочая группа по вопросам развития уголовного права. В проекте Уголовного кодекса, подготовленного этой группой, уголовная ответственность в сфере равноправия граждан закреплена в статье 4.12.4. «Дискриминация»
Раздела 4.12. «Преступления и проступки против равноправия и других политических прав граждан» Книги четыре «Преступления и проступки против человека и гражданина». Диспозиция этой нормы определяет, что лицо, прямо или косвенно по признакам расы, цвета кожи, политических, религиозных или других убеждений, пола, инвалидности или состояния здоровья, этнического или социального происхождения, имущественного состояния, местожительства, по языковым или другим признакам а) ограничило равное право на доступ к государственной службе или службе в органах местного самоуправления, б) нарушило равенство прав женщины и мужчины, в) ограничило другое конституционное право человека или гражданина; г) установило для человека прямые или косвенные привилегии, - совершает преступление 3 степени [10, с.80-81].

Соглашаясь в общем с содержанием вышеуказанной нормы, следует заметить, что, по нашему мнению, не совсем удачным является употребление термина «лицо», ведь дискриминационные действия могут совершать коллективные органы или лица, действующие от имени государства или государственных органов, или органов местного самоуправления, что может затруднить квалификацию таких деяний на практике.

Также следует положительно оценить выделение авторами проекта из состава нарушение равноправия граждан (дискриминации) в отдельный состав уголовное преступление, предусматривающей ответственность за разжигание вражды и ненависти. В частности, уголовные ответственность за такое деяние предусматривается статьей 4.12.3. «Возбуждение вражды или ненависти» того же раздела, где лицо, которое: а) разжигало или пропагандировало национальную, расовую или религиозную вражду, или ненависть или вражду, или ненависть по признаку региональной принадлежности, б) унижало национальную честь или достоинство; в) оскорбляло чувства граждан в связи с их религиозными убеждениями, - совершает преступление 3 степени.

Вместе с тем, авторы проекта оставляют в содержании нормы термин «разжигание», употребляемый в данном случае в переносном смысле, что однозначно создает трудности при квалификации такого деяния. Кроме этого, по нашему мнению, учитывая обоснованные результаты собственного диссертационного исследования, является ошибочным размещения этого состава правонарушения в вышеупомянутом разделе, а не в разделе 7.1. «Преступления против государственной безопасности» Книги семь «Преступления и проступки против государства».

Стоит отметить, что Раздел 4.12. данного проекта в статье 4.12.2. содержит такой квалифицирующий признак состава преступления, которая повышает на одну ступень тяжесть преступлений, предусмотренных настоящим 
разделом, как причинение массовых беспорядков. Вместе с тем, по нашему мнению, не совсем обоснованной выглядит позиция авторов проекта об отказе от таких квалифицирующих признаков, как совершение представителем власти или должностным лицом с использованием служебного положения, или повторно, или по предварительному сговору группой лиц, или с использованием средств массовой информации, компьютерных сетей или сетей электросвязи, или в сочетании с призывами к насилию, организованной группой, или если такие действия повлекли тяжкие последствия.

Выводы и перспективы дальнейших исследований. Учитывая изложенное, следует отметить, что уголовное законодательство Украины и Молдовы содержит норму, которая обеспечивает уголовно-правовую охрану общественным отношениям в сфере соблюдения принципа равноправия граждан. Вместе с тем, уголовноправовая норма законодательства Украины содержит в своем составе деяния, которые посягают на безопасность в сфере межнациональных, межрасовых и межрелигиозных отношений. Такие же деяния в уголовном законодательстве Молдовы закреплены в отдельной уголовно-правовой норме. Конструктивные элементы уголовно-правовых норм Украины и Молдовы, которые обеспечивают уголовно-правовую охрану общественных отношений в сфере равноправия граждан и безопасности межнациональных, межрасовых и межрелигиозных отношений, имеют отдельные недостатки, что обуславливает необходимость на основании тщательного научного исследования эмпирического материала усовершенствования действующего уголовного законодательства обеих стран.

\section{Библиографические сноски:}

1. Категоризация и расследование преступлений на почве ненависти в Украине Практическое пособие. Опубликовано Бюро демократических институтов и прав человека ОБСЕ (БДИПЧ), Варшава, 2019,74 с.).

2. Конституция Украины: Закон Украины №254к/96-ВР от 28 июня 1996 года. Ведомости Верховной Рады Украины (ВВР), 1996, № 30, ст. 141.

3. Конституция Республики Молдова от 29.03.2016, Monitorul Oficial Nr. 78 статья №: 140. URL: https://www.presedinte.md/rus/constitution

4. Уголовный кодекс Украины Закон Украины № 2341-III от 5 апреля 2001 года. Ведомости Верховной Pады Украины (ВВР), 2001, № 25-26, ст.131.

5. Уголовный кодекс Республики Молдова от 18 апреля 2002 года № 985-XV (с изменениями и дополнениями по состоянию на 23.04.2021г.). URL: http://continent-online.com/Document/?doc id=30394923 (посещение 12.09.2021).

6. Панькевич В.Н. Уголовно-правовая характеристика нарушения равноправия граждан в связи с их расовой, национальной принадлежностью или отношения к религии. Автореф. дис. на соискание учёной степени к.ю.н. КНУВД, Киев, 2010. 20 с.

7. Кудрявцев В. Н. Объективная сторона преступления. М.: Наука, 1960. 298 с.

8. Карпушин М. П., Курляндський В. И. Уголовная ответственность и состав преступления. М., Юридическая литература, 1974. 232 с.

9. Тростюк 3. А. Понятийный аппарат Особенной части Уголовного кодекса Украины. К.: Атика, 2003. $144 \mathrm{c}$.

10. Проект Уголовного кодекса Украины, подготовленного Рабочей группой по вопросам развития уголовного права по состоянию на 25.07.2021г. 129c. URL: https://newcriminalcode.org.ua/criminal-code (посещение 22.09.2021). 